\title{
The effects of auto-tempering martensite on mechanical strength of a microalloyed steel containing boron and titanium
}

\author{
Wagner Monteiro de Souza ${ }^{1^{*}}$ \\ André Itman Filho ${ }^{2}$ \\ Rosana Vilarim da Silva ${ }^{2}$ \\ João Batista Ribeiro Martins ${ }^{3,2}$ \\ Luciana Xavier da Cruz Lima ${ }^{3}$
}

\begin{abstract}
Oil Country Tubular Goods (OCTG) steels are used in the form of tubes in the casing column of the oil well walls and exhibit tempered martensitic structure after quenching and tempering. In these steels, due to the high cost of chromium, nickel and molybdenum, an alternative is the replacement of these elements by boron, which increases the hardenability. In order to maintain the efficiency of boron in solution during the quenching, it is necessary to add titanium to form titanium nitrides (TiN), which inhibit austenitic grain growth and avoid the formation of boron nitride. Another factor is to evaluate the effect of heat treatment on the mechanical properties of this steel. In the present study were evaluated the microstructure, hardness and tensile properties of a microalloyed hot rolled steel containing boron and titanium after heat treatments. Samples of a coil were quenched at 850 and $1050^{\circ} \mathrm{C}$ and then tempered at 200 and $600^{\circ} \mathrm{C}$. The results show that the hardness, yield stress and tensile strength after austenitization temperature at $1050^{\circ} \mathrm{C}$ are smaller, due to the formation of auto-tempering martensite in the quenching.
\end{abstract}

Keywords: Boron steels; Titanium nitride; Auto-tempering martensite; Hardenability.

\section{Introduction}

OCTG steels are used in the manufacture of tubes to be applied as columns in the oil wells. The steels used in these columns must provide compatible hardness with the tensile properties, as well as corrosion and abrasion resistance, with the minimum wall thickness.

The heat treatment are responsible for meeting the requirements of API SPECT 5CT standard and is closely associated with the transformation and morphology of martensite. According to the literature, the martensite transformation accompanied with auto-tempering would occur at the coiling temperature, because the residual heat is difficult to transfer into surroundings [1]. In this case, the softening of martensite after auto-tempering is associated with the migration of carbon atoms, precipitation of particles and recovery of dislocation structure [2]. However, many researches also demonstrated, that carbon and nitrogen could segregate, pin the dislocations and increase mechanical properties, when the tempering temperature increased to $\pm 250^{\circ} \mathrm{C}[3,4]$.

Another important factor in the quality of OCTG steels is the chemical composition. Due to the high cost of chromium, nickel and molybdenum, boron is added as an alternative chemical element to increase the hardness, yield strength and tensile strength. Boron is an interstitial element with low solubility in ferrite and is added in the range of 10 to $30 \mathrm{ppm}$ in steel. Boron segregates in grain boundaries, inhibits the ferritic nucleation and favors the martensitic transformation [5]. In order to maintain the efficiency of boron in solid solution it is necessary to add titanium to stabilize nitrogen by forming titanium nitride (TiN), instead of boron nitride. Titanium nitride hinders grain growth at soaking temperatures [6]. In this context, the objective of this research was to evaluate the effects of coiling temperatures at 200 and $600^{\circ} \mathrm{C}$ on the mechanical properties of one oil country tubular goods steel, considering the formation of autotempering martensite. To simulate the coiling temperatures, samples of the plates were subjected to heat treatments of quenching and tempering at different temperatures. The effect of nitrogen and boron was observed by microstructural characterization after quenching and tempering at different temperatures. The austenitization temperatures, close to and above $\mathrm{Ac}_{3}$, were chosen to evaluate the effect of titanium nitride on grain size.

\footnotetext{
${ }^{1}$ ArcelorMittal Tubarão, Serra, ES, Brasil.

${ }^{2}$ Instituto Federal do Espirito Santo - IFES, Vitória, ES, Brasil.

${ }^{3}$ Global R\&D South America - ArcelorMittal, Serra, ES, Brasil.

“Corresponding author: wagnermonteirosouza@hotmail.com
} 


\section{Materials and methods}

The steel was prepared in a converter and continuous casting into slabs of $6.0 \times 1.5 \times 0.2 \mathrm{~m}$. The slabs were heated up to $1200{ }^{\circ} \mathrm{C}$ and were continuously hot rolled into a thickness

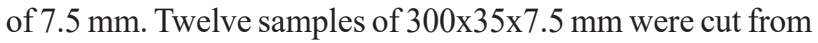
one of these plates in the longitudinal direction of rolling. Six samples were heated in an electric furnace at $850^{\circ} \mathrm{C}$ for 30 minutes and then water quenched. Further, three of them were tempered at $200^{\circ} \mathrm{C}$ and three at $600^{\circ} \mathrm{C}$ for 50 minutes. The other six samples were heated at $1050^{\circ} \mathrm{C}$ for 30 minutes and then water quenched. The tempering was similar to that of quenched at $850^{\circ} \mathrm{C}$. After quenching and tempering, the samples were cooled in water at $23{ }^{\circ} \mathrm{C}$ and the cooling rate was controlled in the range of 10 to $50^{\circ} \mathrm{C}$ per minute. In this research, two different austenitization temperatures were used to evaluate the effect of titanium nitride on the size of the austenitic grain. Regarding tempering temperatures, they can be controlled in the coiling, after rolling, to obtain different mechanical properties in steel. Afterward, specimens as ASTM E8/E8M, were submitted to tensile tests in an universal hydraulic test machine with a capacity of $500 \mathrm{kN}$ and strain gauge with measurable deformation of $50 \mathrm{~mm}$.

Three specimens in each condition were pulled with $1 \mathrm{~mm}$ per minute constant speed. To reveal the microstructure the tensile tests specimens were prepared according to conventional metallographic methods and were immersed in 2\% Nital reagent ( $2 \%$ nitric acid in ethyl alcohol) for approximately 30 seconds. Lepera reagent ( $1 \%$ sodium metabisulfide in water plus $4 \%$ picric acid in ethyl alcohol) was prepared to reveal the autotempering martensite and ferric chloride reagent $\left(5 \mathrm{~g} \mathrm{FeCl}_{3}\right.$, $50 \mathrm{ml} \mathrm{HCl}$ and $100 \mathrm{ml} \mathrm{H}_{2} \mathrm{O}$ ) to evaluate the austenitic grain size.
The microstructures were characterized by Scanning Electronic Microscope (SEM) with Energy Dispersive Spectrometry (EDS) system. The hardness of the matrix and phases were measured by Vickers hardness with load of $10 \mathrm{kgf}$ and Vickers microhardness with load of 50 gf considering the ISO 6507-1 standard. Results represent the average of five measurements in each specimen after quenching and tempering. The austenitic grain sizes were measured according to ASTM E112.

\section{Results}

Table 1 shows the chemical composition of the microalloyed steel. Figures $1 \mathrm{a}$ and $1 \mathrm{~b}$ show the microstructures of martensite laths after quenching at 850 and at $1050^{\circ} \mathrm{C}$, respectively. Figures $2 \mathrm{a}$ and $2 \mathrm{~b}$, after quenching at 850 and at $1050^{\circ} \mathrm{C}$, show the martensite laths (blue color) and autotempering martensite (brown color). Figures $3 \mathrm{a}$ and $3 \mathrm{~b}$ show the microstructures after quenching at 850 and $1050^{\circ} \mathrm{C}$ and tempering at $200^{\circ} \mathrm{C}$, respectively. Figures $4 \mathrm{a}$ and $4 \mathrm{~b}$ show coalesced carbides in the steel after quenching at 850 and $1050^{\circ} \mathrm{C}$ and tempering at $600^{\circ} \mathrm{C}$ [7]. Table 2 and Figures 5a and $5 \mathrm{~b}$ show the austenitic grain size, after quenching at 850 and $1050^{\circ} \mathrm{C}$. Figure 6 a shows the eutectic titanium nitride and Figure $6 \mathrm{~b}$ the EDS spectrum. Table 2 and Figures $5 \mathrm{a}$ and $5 \mathrm{~b}$ show the austenitic grain size, after quenching at 850 and $1050^{\circ} \mathrm{C}$. Table 3 shows the averages of five Vickers microhardness measurements of martensite and auto-tempering martensite in the steel, after quenching at different temperatures. Table 4 presents the average of five values of Vickers hardness, yield strength $\left(\sigma_{\mathrm{e}}\right)$, tensile strength $\left(\sigma_{\max }\right)$ and elongation, after quenching and tempering at different temperatures.

Table 1. Chemical composition of the microalloyed steel (\% in weight)

\begin{tabular}{ccccccccccc}
\hline $\mathbf{C}$ & Mn & Si & P & S & Ti & B & Fe \\
\hline 0.23 & 1.26 & 0.24 & 0.013 & 0.0018 & 0.019 & 0.005 & 0.0013 & Balance \\
\hline
\end{tabular}
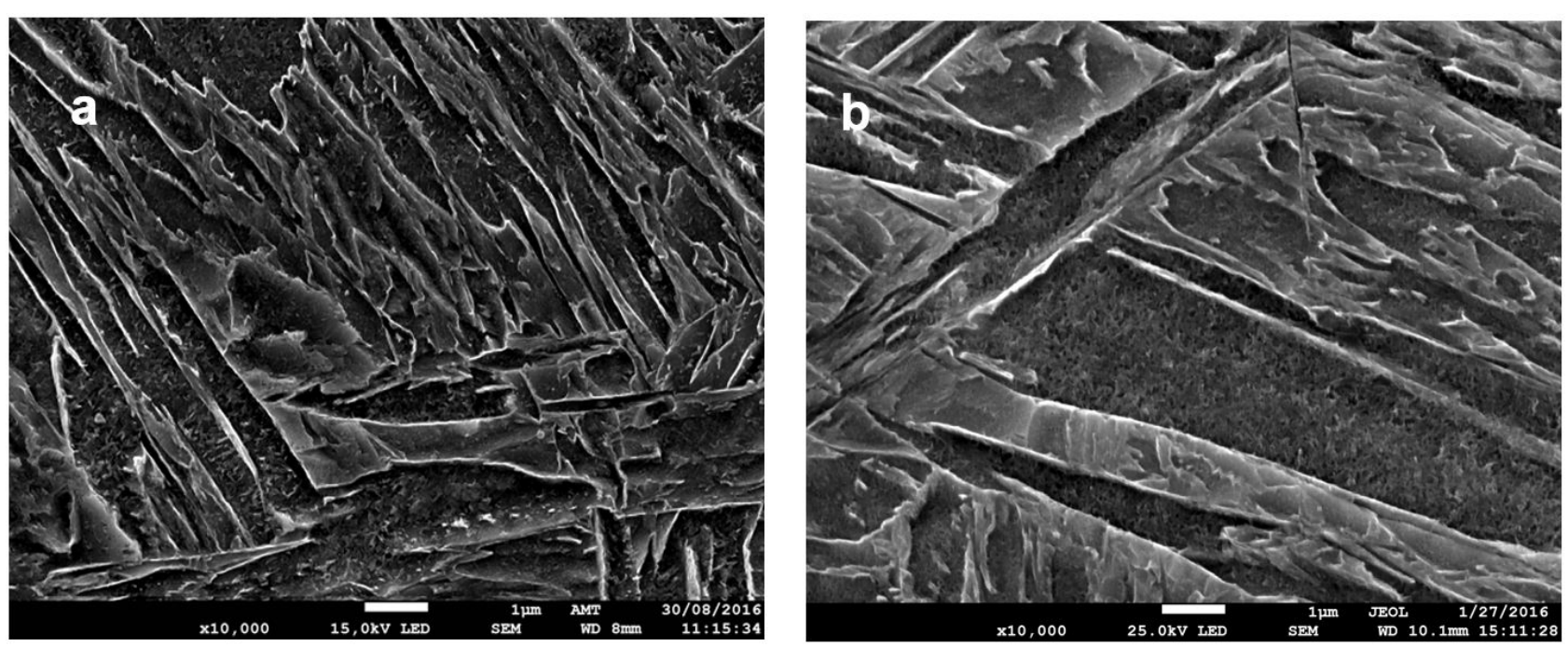

Figures 1. (a) and (b) Martensite laths after quenching at $850^{\circ} \mathrm{C}$ and $1050^{\circ} \mathrm{C}(2 \% \mathrm{Nital}, \mathrm{SEM})$. 

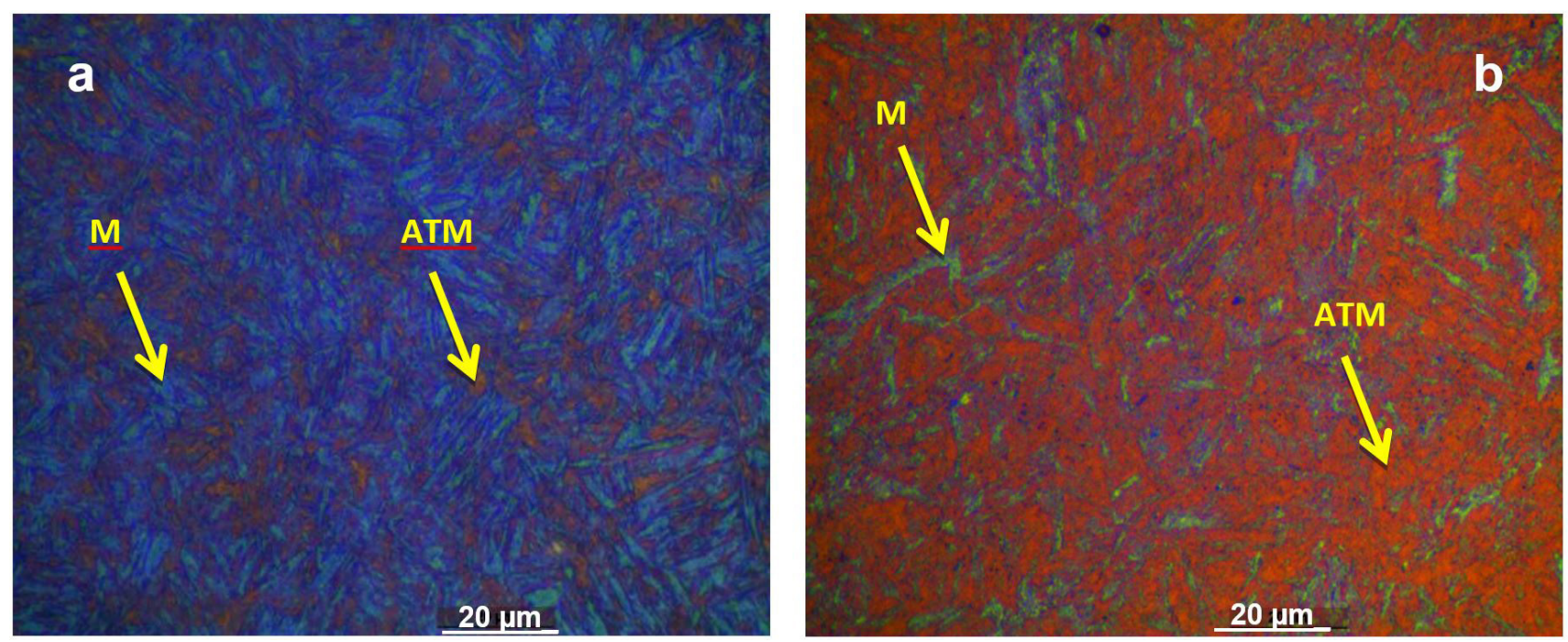

Figures 2. (a) and (b) Blue regions of martensite laths (M) and brown regions of auto-tempering martensite (ATM). Quenching at $850^{\circ} \mathrm{C}$ and $1050^{\circ} \mathrm{C}$ (Lepera, OM).
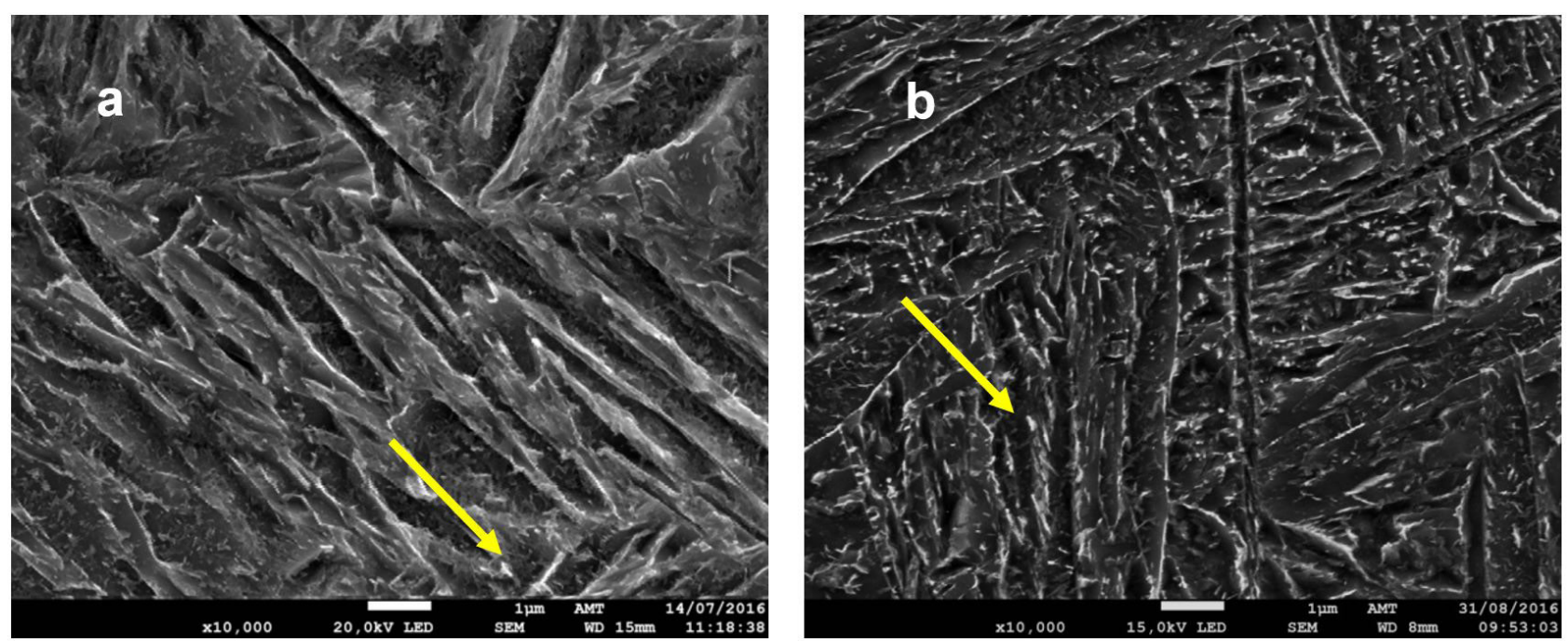

Figures 3. (a) and (b) Tempered martensite and carbides precipitation in the matrix after quenching at $850^{\circ} \mathrm{C}$ plus tempering at $200^{\circ} \mathrm{C}$ and quenching at $1050^{\circ} \mathrm{C}$ plus tempering at $200^{\circ} \mathrm{C}(2 \%$ Nital, SEM).
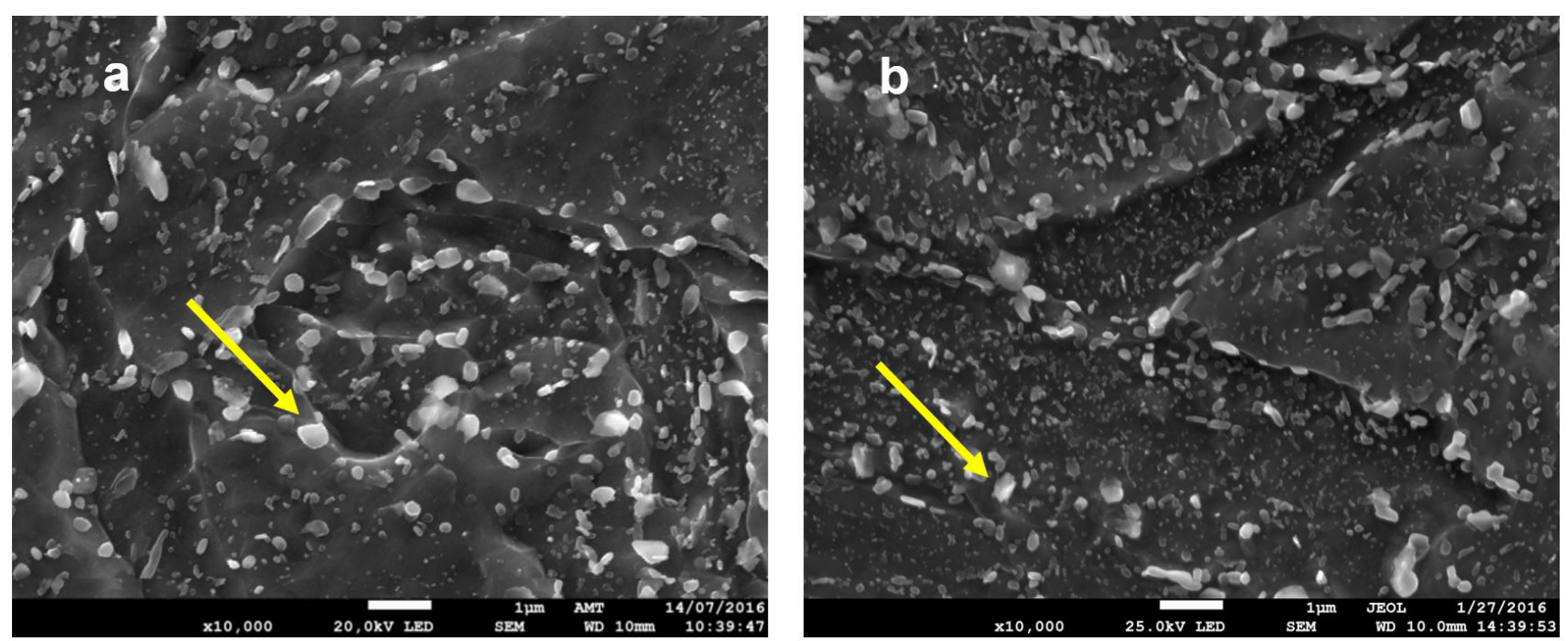

Figures 4. (a) and (b) Tempered martensite with coalesced carbides in the matrix after quenching at $850^{\circ} \mathrm{C}$ plus tempering at $600^{\circ} \mathrm{C}$ and quenching at $1050^{\circ} \mathrm{C}$ plus tempering at $600^{\circ} \mathrm{C}(2 \%$ Nital, SEM $)$. 

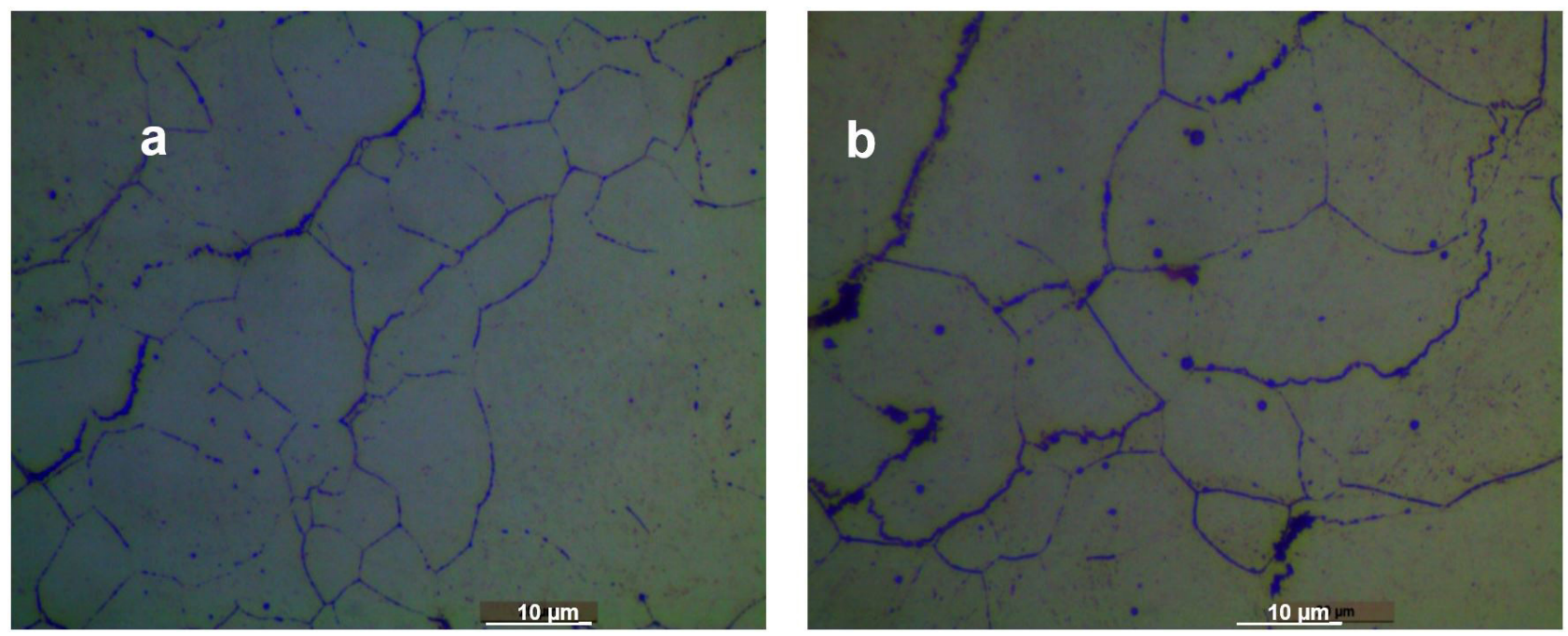

Figures 5. (a) and (b) Austenitic grain size after quenching at $850^{\circ} \mathrm{C}$ and $1050^{\circ} \mathrm{C}$ (Ferric chloride-MO).
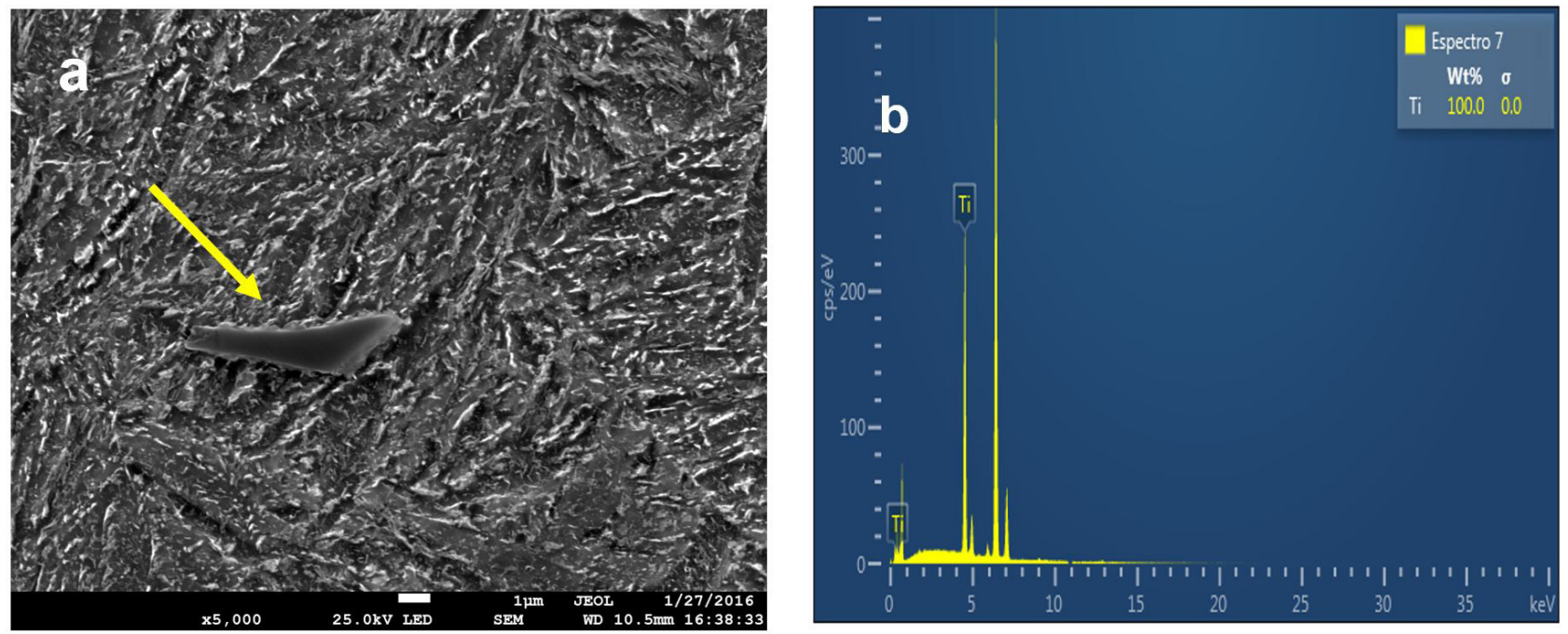

Figure 6. (a) and (b) Morphological characteristic of titanium nitride and the EDS spectrum (2\% Nital, SEM).

Table 2. The austenitic grain size after quenching at different temperatures according ASTM E112

\begin{tabular}{ccc}
\hline Temperature & Grain Size (ASTM) & $\boldsymbol{\mu} \mathbf{m}$ \\
\hline $850^{\circ} \mathrm{C}$ & $7.0 \pm 0.5$ & $32 \pm 1$ \\
$1050^{\circ} \mathrm{C}$ & $8.0 \pm 0.5$ & $23 \pm 2$ \\
\hline
\end{tabular}

Table 3. Vickers microhardness of martensite and auto-tempering martensite (AT Martensite)

\begin{tabular}{ccc}
\hline Quenching & Martensite (HV) & AT Martensite (HV) \\
\hline $850^{\circ} \mathrm{C}$ & $504 \pm 10$ & $439 \pm 10$ \\
$1050^{\circ} \mathrm{C}$ & $493 \pm 10$ & $430 \pm 15$ \\
\hline
\end{tabular}

\section{Discussion}

The N/Ti ratio of 3.8, in the chemical composition in Table 1, indicates that all nitrogen is bound to titanium. So boron is free in solid solution to be effective to form martensite laths after quenching $[5,8]$. The microstructures of martensite laths
Table 4. Vickers hardness, yield strength $\left(\sigma_{\mathrm{e}}\right)$, tensile strength $\left(\sigma_{\max }\right)$ and elongation after quenching $(\mathrm{Q})$ and quenching plus tempering $(\mathrm{Q}+\mathrm{T})$ of steel

\begin{tabular}{ccccc}
\hline & Temperature & $\mathbf{Q}$ & $\mathbf{Q}+\mathbf{T ~ 2 0 0}{ }^{\circ} \mathbf{C}$ & $\mathbf{Q}+\mathbf{T ~ 6 0 0} \mathbf{~}^{\circ} \mathbf{C}$ \\
\hline Hardness & $850^{\circ} \mathrm{C}$ & $400 \pm 10$ & $440 \pm 11$ & $213 \pm 5$ \\
$(\mathrm{HV})$ & $1050^{\circ} \mathrm{C}$ & $344 \pm 5$ & $359 \pm 6$ & $201 \pm 4$ \\
& $850^{\circ} \mathrm{C}$ & $1018 \pm 10$ & $1198 \pm 11$ & $517 \pm 7$ \\
$\sigma_{\mathrm{e}}(\mathrm{MPa})$ & $1050^{\circ} \mathrm{C}$ & $934 \pm 9$ & $1113 \pm 13$ & $489 \pm 5$ \\
& $850^{\circ} \mathrm{C}$ & $1509 \pm 13$ & $1449 \pm 12$ & $624 \pm 7$ \\
$\sigma_{\max }(\mathrm{MPa})$ & $1050^{\circ} \mathrm{C}$ & $1382 \pm 12$ & $1376 \pm 11$ & $612 \pm 6$ \\
Elongation & $850^{\circ} \mathrm{C}$ & $10 \pm 1$ & $12 \pm 2$ & $27 \pm 3$ \\
$(\%)$ & $1050^{\circ} \mathrm{C}$ & $12 \pm 2$ & $12 \pm 1$ & $27 \pm 3$ \\
\hline
\end{tabular}

is favored by quenching temperatures above $800^{\circ} \mathrm{C}$ in boron steels [9]. In this case, the temperature $\mathrm{Ac}_{3}$ is approximately $780^{\circ} \mathrm{C}$, according to the Kasatkin equation [10]. Regarding the Vickers hardness it is possible to observe in Table 4, after quenching and quenching plus tempering, that the values at 1050 are less than $850^{\circ} \mathrm{C}$. This can be explained by the 
larger grain size and the greater amount of auto-tempering martensite after quenching at $1050^{\circ} \mathrm{C}$. The auto-tempering microstructure is associated with the migration of carbon and carbide precipitation at the martensite, and according to the literature, improves the plasticity of the steel [6]. The characterization was possible with Lepera reagent attack that shows the initial martensite (blue color) and the autotempering martensite (brown color), besides microhardness measurements in these regions. It can be seen at $1050^{\circ} \mathrm{C}$ a greater amount of auto-tempering martensite formed in the cooling to room temperature. It is likely, that the solubility of carbon in austenite favors the higher amount of autotempering martensite [1]. The values in Table 3 confirm the microhardness differences between martensites after quenching, due to the c/a variation of the body centered tetragonal structure $[11,12]$. In steels with more than $0.2 \%$ carbon, after tempering in the range of 100 to $250^{\circ} \mathrm{C}$, it is possible that transition carbides less than 100 angstron precipitate from martensite and hinder the dislocations movement. These constituents nuclei and grow faster than cementite [13,14]. Although, other researchers connect this mechanism to the nitrogen and carbon interstitials, both cases explain the increase in the hardness and yield stress values shown in Table $4[3,4]$.

With regard to the temperature at $600^{\circ} \mathrm{C}$, the carbides coalesce (Figures $4 a$ and $4 b$ ) and favors the decrease of hardness, the yield strength and the tensile strength, but increases elongation, as shown in Table 4 [7,12]. Unlike Figures 3a and $3 \mathrm{~b}$ with a small amount of cementite, the microstructure presents an aggregate of tempered martensite with a large number of spheroidal iron carbides. According to Table 4, coalescence is likely to be more important than differences in austenitic grain and martensite packet size. With relation to the austenitic grain sizes, the values, after quenching at 850 and $1050^{\circ} \mathrm{C}$, are in the range of seven to eight ASTM as shown in Table 2 and Figures 5a and 5b [15-17]. It is possible that titanium nitrides promote the refining of the austenitic grain during rolling at $1200^{\circ} \mathrm{C}$ and after quenching at 850 and $1050^{\circ} \mathrm{C}$ the values are similar [18]. Then it will be possible to obtain different mechanical properties with a lower austenitization temperature and, therefore, reduce the cost of heat treatment. In addition, tempering temperatures can be controlled in the coiling. Figure 6a shows the eutectic titanium nitride. The EDS spectrum in Figures $6 \mathrm{~b}$ confirms the chemical composition of the precipitate.

\section{Conclusions}

- After quenching, auto-tempering martensite associated with austenite grain and martensite packet sizes, promotes the values reduction of hardness, yield strength and tensile strength of the steel;

- Lepera reagent and Vickers microhardness measurements allows the identification of auto-tempering martensite;

- Titanium nitride inhibits the austenitic grain growth and the values are similar after austenitization in the range of 850 to $1050^{\circ} \mathrm{C}$.

\section{Acknowledgements}

The authors thank Global R\&D South America ArcelorMittal for the steel used in this work.

\section{References}

1 Li C, Yuan G, Ji F, Ren D, Wang G. Effects of auto-tempering on microstructure and mechanical properties in hot rolled plain C-Mn dual phase steels. Materials Science and Engineering A. 2016;665:98-107.

2 Ohlund CEIC, Schlangen E, Erik Offerman S. The kinetics of softening and microstructure evolution of martensite in Fe-C-Mn steel during tempering at $300^{\circ} \mathrm{C}$. Materials Science and Engineering A. 2013;560:351-357.

3 Kamp A, Celotto S, Hanlon DN. Effects of tempering on the mechanical properties of high strength dual-phase steels. Materials Science and Engineering A. 2012;538:35-41. http://dx.doi.org/10.1016/j.msea.2012.01.008.

4 Gündüz S. Static strain ageing behaviour of dual phase steels. Materials Science and Engineering A. 2008;486(12):63-71. http://dx.doi.org/10.1016/j.msea.2007.08.056.

5 Ghali SN, El-Faramawy HS, Eissa MM. Influence of boron additions on mechanical properties of carbon steel. Scientif Research. 2012;11(10):995-999.

6 Panigrahi BK. Processing of low carbon steel plate and hot strip. Bulletin of Materials Science. 2001;24(4):361-371. http://dx.doi.org/10.1007/BF02708632.

7 Cruz JA Jr, Santos DB. Effect of tempering temperature on isothermal decomposition product formed below Ms. Journal of Materials Research and Technology. 2013;2(2):93-99. http://dx.doi.org/10.1016/j.jmrt.2012.11.001.

8 Shen Y, Hansen SS. Effect of the Ti/N ratio on the hardenability and mechanical properties of a Quenched-andTempered C-Mn-B steel. Metallurgical and Materials Transactions. A, Physical Metallurgy and Materials Science. 1997;28(10):2027-2035. 
9 Frantov II, Golovanenko SA, Moiseev BA, Burnyashev II. Effect Influence of heat treatment on the effectiveness of microalloying of pipe steels. Metallovedenie i Termicheskaya Obrabotka Metallov. 1980;(11):51-54.

10 Kasatkin OG, Vinokur BB, Pilyushenko VL. Calculation models for determining the critical points of steel. Metal Science and Heat Treatment. 1984;26(1):27-31.

11 Matsuda H, Mizuno R, Funakawa Y, Seto K, Matsuoka S, Tanaka Y. Effects of auto-tempering behaviour of martensite on mechanical properties of ultra high strength steel sheets. Journal of Alloys and Compounds. 2013;577:661-667.

12 Nishibata T, Kojima N. Effect of quenching rate on hardness and microstructure of hot stamped steel. Journal of Alloys and Compounds. 2013;577:S549-S554. http://dx.doi.org/10.1016/j.jallcom.2011.12.154.

13 Speich GR, Leslie WC. Tempering of steel. Metallurgical Transactions. 1972;3(5):1043-1054.

14 Reed-Hill RE. Physical metallurgy principles. 4th ed. Stamford: Cengage Learning; 2009.

15 Cuddy LJ, Raley JC. Austenite grain coarsening in microalloyed steels. Metallurgical Transactions. A, Physical Metallurgy and Materials Science. 1983;14(10):1989-1995.

16 Gladman T. Precipitation hardening in metals. Materials Science and Technology. 1999;15(1):30-36.

17 Itman A, Silva RV, Souza WM, Martins JB, Casteletti LC, Totten GE. Effect of quenching and tempering in microalloyed steels containing boron and titanium. In: Proceedings of the 23rd International Federation of Heat Treatment and Surface Engineering Congress, 2016; Savannah, GA, USA. Materials Park: ASM; 2016. p. 536-540.

18 Korchynsky M. Application of titanium-nitride for grain refinement. In: Proceedings of the 35th Mechanical Working and Steel Processing Conference; 1993; Pittsburgh, PA, USA. Pittsburgh: ISS; 1993.

Received: 3 Sep. 2019

Accepted: 6 Jul. 2020 